Original article

\title{
Psychological distress during pandemic Covid-19 among adult general population: Result across 13 countries
}

\author{
Roy Rillera Marzo ${ }^{\text {a, }}$, Zaliha Ismail ${ }^{\text {b }}$, Mila Nu Nu Htay ${ }^{c}$, Rafidah Bahari $^{\mathrm{d}}$, Roshidi Ismail ${ }^{\mathrm{e}}$, \\ Emilio Quilatan Villanueva III ${ }^{\mathrm{f}}$, Akansha Singh ${ }^{\mathrm{g}}$, Masoud Lotfizadeh ${ }^{\mathrm{h}}$, Titik Respati ${ }^{\mathrm{i}}$, \\ Siska Nia Irasanti ${ }^{j}$, Dewi Sartika ${ }^{k}$, Pham Mong ${ }^{1}$, Sarath Lekamwasam ${ }^{\mathrm{m}}$, Bikash Bikram Thapa ${ }^{\mathrm{n}}$, \\ Burcu Kucuk Bicer ${ }^{\circ}$, Soe Soe Aye ${ }^{\mathrm{p}}$, Karnjana Songwathana ${ }^{\mathrm{q}}$, Radwa Abdullah El-Abasiri ${ }^{\mathrm{r}}$, \\ Amaluddin Ahmad $^{\mathrm{p}}$, AzlinaWati Nikmat ${ }^{\mathrm{s}}$, Seyedeh Zeinab Taheri Mirani ${ }^{\mathrm{t}}$, \\ Roushney Fatima Mukti ${ }^{\mathrm{u}}$, Saira Mehnaz ${ }^{\mathrm{v}}$, Tin Tin $\mathrm{Su}^{\mathrm{e}}$
}

${ }^{a}$ Department of Community Medicine, Faculty of Medicine, Asia Metropolitan University, Malaysia

${ }^{\mathrm{b}}$ Department of Public Health Medicine, Faculty of Medicine, Universiti Teknologi MARA, Malaysia

${ }^{\mathrm{c}}$ Department of Community Medicine, Melaka-Manipal Medical College, Manipal Academy of Higher Education (MAHE), Melaka, Malaysia

${ }^{\mathrm{d}}$ Department of Psychiatry, Faculty of Medicine, University of Cyberjaya, Malaysia

${ }^{\mathrm{e}}$ South East Asia Community Observatory (SEACO) \& Global Public Health, Jeffery Cheah School of Medicine and Health Sciences, Monash University Malaysia,

Malaysia

${ }^{\mathrm{f}}$ Department of Pathology, College of Medicine, University of the Philippines, Philippines

${ }^{g}$ Durham University, United Kingdom

${ }^{\mathrm{h}}$ Social Determinants of Health Research Center, Shahrekord University of Medical Sciences, Shahrekord, Iran

i Department of Public Health, Faculty of Medicine and Faculty of Graduate Studies, Universitas Islam Bandung, Indonesia

${ }^{\mathrm{j}}$ Department of Public Health, Faculty of Medicine, Universitas Islam Bandung, Indonesia

${ }^{\mathrm{k}}$ Faculty of Psychology, Universitas Islam Bandung, Indonesia

${ }^{1}$ University of Economics, Ho Chi Minh City, Viet Nam

${ }^{\mathrm{m}}$ Faculty of Medicine, Karapitiya, Galle, Sri Lanka

${ }^{n}$ Consultant Surgeon \& Public Health Scholar, Nepalese Army Institute of Health Sciences, College of Medicine, Nepal

${ }^{\circ}$ Gazi University, Faculty of Medicine, Department of Medical Education and Informatics, Ankara, Turkey

${ }^{\mathrm{p}}$ Department of Pediatrics, Faculty of Medicine, Asia Metropolitan University, Malaysia

${ }^{\mathrm{q}}$ Faculty of Economics and Investment, Bangkok University, Thailand

${ }^{\mathrm{r}}$ Department of Pharmacy Practice and Clinical Pharmacy, Faculty of Pharmaceutical Sciences and Pharmaceutical Industries, Future University in Egypt, Cairo, Egypt

${ }^{s}$ Department of Psychiatry, Faculty of Medicine, Universiti Teknologi MARA (UiTM), Selangor, 40450, Malaysia

${ }^{\mathrm{t}} \mathrm{PhD}$ Candidate in Biomedicine, Monash University, Malaysia

u , Department of Genetic Engineering and Biotechnology, Institution: East West University, Dhaka, Bangladesh

${ }^{v}$ Department of Community Medicine, Jawaharlal Nehru Medical College, Aligarh Muslim University, Aligarh, India

\section{A R T I C L E I N F O}

Keywords:

COVID-19 Peritraumatic Distress Index (CPDI)

Pandemic

Distress

COVID-19

Coronavirus

\begin{abstract}
A B S T R A C T
The COVID-19 pandemics caused an unprecedented mortality, distress, and globally poses a challenge to mental resilience. To our knowledge, this is the first study that aimed to investigate the psychological distress among the adult general population across 13 countries. This cross-sectional study was conducted through online survey by recruiting 7091 respondents. Psychological distress was evaluated with COVID-19 Peritraumatic Distress Index (CPDI). The crude prevalence of psychological distress due to COVID-19 is highest in Vietnam, followed by Egypt, and Bangladesh. Through Multivariate Logistic Regression Analysis, the respondents from Vietnam holds
\end{abstract}

* Corresponding author.Department of Community Medicine, Faculty of Medicine, Asia Metropolitan University, Malaysia

E-mail addresses: rrmtexas@yahoo.com (R.R. Marzo), zaliha78@uitm.edu.my (Z. Ismail), drmlnnh@gmail.com (M.N. Nu Htay), rafidahbahari@cyberjaya.edu.my

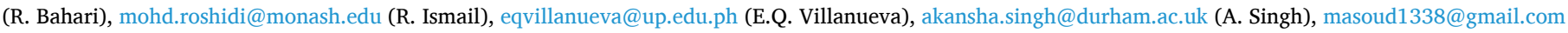

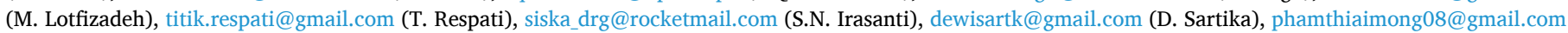

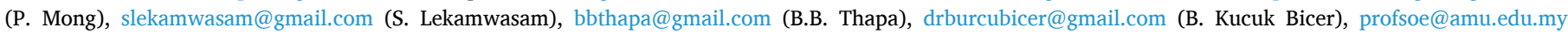

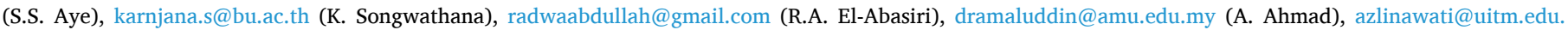

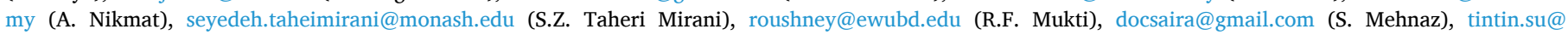
monash.edu (T.T. Su). 
Mental health

Psychological distress the highest level of distress, while the respondents from Sri Lanka holds the lowest level of distress with reference to Nepal.Female respondents had higher odds of having reported psychological distress, and those with tertiary education were less likely to report psychological distress compared to those with lower level of education. The findings indicate that psychological distress is varies across different countries. Therefore, different countries should continue the surveillance on psychological consequences through the COVID-19 pandemic to monitor the burden and to prepare for the targeted mental health support interventions according to the need. The coping strategies and social support should be provided especially to the lower educational attainment group.

\section{Introduction}

The coronavirus disease (COVID-19) pandemic started in China in the late 2019. COVID-19 has infected humans which has caused unprecedented numbers of illness and deaths and has led to psychological distress. COVID-19 poses a challenge to mental resilience globally. ${ }^{1,2}$ As a response toCOVID-19 pandemic, most countries have implemented a measure to prevent the spread of the disease, such as restricting movement. The restriction of movement and quarantine has affected many aspects of people's lives and livelihoods. It may also trigger a wide range of psychological distress and responses such as panic, anxiety, and depression, and it was a predictor of short-term dysfunction to predict the development and/or maintenance of post-traumatic stress disorder $(\mathrm{PTSD})^{3}$ after the pandemic. Many studies showed the adverse psychological health effects following quarantine which include emotional disturbance, depression, stress, low mood, irritability, insomnia, post-traumatic stress symptoms, anger, and emotional exhaustion. ${ }^{4-10}$ The reported adverse psychological effects following quarantine include post-traumatic stress symptoms, confusion, anger, stress due to longer quarantine duration, fear of contracting the virus, frustration, boredom, inadequate supplies, inadequate information, financial loss, and stigma. ${ }^{11}$ Ethnic group differences, to some extent, have contributed to the level of psychological distress. ${ }^{12-14}$ Differences in ethnic inequality demonstrated inequalities in psychological distress due to sociodemographics and economic differences. ${ }^{12}$ Islam (2019) found that a low level of education, inability to work, and residence in semi-urban areas in Bangladesh were associated with a high prevalence of psychological distress. ${ }^{15}$ However, there is a limited information on comparison of the psychological distress and mental health effect of COVID-19 across different countries. The corona virus impacts on psychological health would have different due to countries having a different situation and deployed different responses toward COVID-19 crisis. Therefore, this study aimed to survey the general population across 13 countries (Bangladesh, Egypt, India, Indonesia, Iran, Malaysia, Myanmar, Nepal, Philippines, Sri Lanka, Thailand, Turkey, and Vietnam) to measure the prevalence and severity of psychological distress.

\section{Methods}

\subsection{Study setting and population}

An internet-based cross-sectional survey was conducted from March to April 2020 during the movement restriction took place. Snowball sampling, a type of convenience sampling method was used for the data collection using research networks of universities, hospitals, friends and their relatives. The study population were adults aged 18 years and above who resided in respective countries for a minimum of one week during the COVID-19 pandemic announcement made by the World Health Organization. The structured online questionnaires were distributed through emails, WhatsApp, Telegram, and other social media platforms throughout different countries. All co-researchers and colleagues identified the respondents' social media account through their link and network.

\subsection{Study tool (measurement)}

Data were collected through a structured online questionnaire. The questionnaire has two parts:Part 1 - Sociodemographic data (state, gender, age, education, marital status, co-morbidities); Part 2 - COVID19 Peritraumatic Distress Index (CPDI), which was developed by Qui et al. ${ }^{16}$ The COVID-19 CPDI was a self-reported questionnaire with 24 questions which features the use of a Likert Scale: (never -0 , occasionally-1, sometimes-2, often-3, and always-4) of anxiety, depression, specific phobias, cognitive change, avoidance, and compulsive behavior, physical symptoms, and loss of social function in the past week.

The questionnaire incorporated relevant diagnostic guidelines for specific phobias and stress disorders specified in the International Classification of Diseases (11th revision) and expert opinions from psychiatrists and psychologists. The total score ranges from 0 to 100. A score between 28 and 51 indicates mild to moderate distress, while a score that is greater than or equivalent to 52 indicates severe distress. ${ }^{16}$ A group of expert panels in the respective countries which included psychiatrists, clinical psychologists, physicians, specialists pharmacists, clinicians and public health experts translated and culturally validated into their national language Bangladesh (Bengali), Egypt (Arabic), India (Hindi), Indonesia (Bahasa Indonesia), Iran (Persian), Malaysia (Bahasa Melayu), Myanmar (Burmese), Nepal (Nepali), Philippines (Tagalog), Sri Lanka (Sinhala), Thailand (Thai), Turkey (Turkish), and Vietnam (Vietnamese).

Pilot testing comprised of 15 participants in each country to test face validity and 50 participants in each country to test the internal consistency. The Cronbach's alpha value ranging from 0.824 in Vietnam to 0.925 in Malaysia indicated that the questionnaire has a good to excellent internal consistency across all countries.

\subsection{Process of data collection}

Data collection started 2 weeks after the announcement by the WHO that COVID-19 was pandemic. The online link was available for about 1 month. Our study was an online survey which was completely voluntary. The consented participants were able to respond only once using a single account by setting the feature to prevent more than one response from the same history. The participants were asked to give a response based on their previous one-week experience. Spreadsheet's responses were exported into IBM SPSS version 25 and Stata 13.0 (Stata Corp., USA). Overall response rate of the survey was $36 \%$.

\subsection{Statistical analyses}

Descriptive statistics was conducted for the demographic variables, and reported with frequency (count), percentage, mean, standard deviation and prevalence. Univariate logistic regression was conducted to produce crude odds ratios for associations between countries, age, sex, religion, education, and employment with distress. A multivariate logistic regression was then fitted to examine the association between distress and countries, with Nepal as a reference category controlling for demographic factors. Nepal was chosen as a reference category due lowest psychological distress prevalence among all 13 countries.

Age, sex, nationality, education, and employment were initially 
included to predict the likelihood of being in distress category. Religion was removed because distribution of religion is not similar in each country. Education level categories were collapsed to two categories (from primary, secondary, and tertiary level to up-to secondary and tertiary) in order to minimize multicollinearity to become an acceptable level. The removal of religion and collapsing education level categories has reduced mean VIF from 3.86 (range 1.16-10.46) to 1.99 (range 1.16-3.62). Statistical analyses were computed IBM SPSS version 25 and Stata 13.0 (Stata Corp., USA).

\section{Results}

A total of 7,091 respondents took part in this online survey conducted in multiple countries. Table 1 showed the sample characteristics which illustrate the majority of the sample were women $(59.8 \%)$, Muslim (61.5\%), had tertiary education (67.6\%), and on employed $57.1 \%)$. About half of the respondents were from Indonesia (15.1\%), Iran (16.4\%) and Malaysia (16.9\%).

The crude prevalence of psychological distress from COVID-19 pandemic is displayed in Table 2 where the crude prevalence is shown in descending order. The top 3 countries that reported the highest prevalence of psychological distress from the pandemic were Vietnam (94.5\%), Egypt (64.1\%) and Bangladesh (56.3\%) whereas the 3 countries in this study that had the lowest prevalence of psychological distress from the COVID-19 pandemic were Thailand, Sri Lanka and Nepal with $28.1 \%, 26.8 \%$ and $14.0 \%$ respectively. As compared to males $(42.2 \%)$, prevalence among females was much higher $(48.0 \%)$. The prevalence of distress was more in higher educated people (Primary/ secondary education- 42.3\%; Tertiary education-47.3\%). Students (41.9\%) had the low level of distress as compared to employed (46.3\%) and unemployed (47.4\%) people.

The univariate and multivariable logistic regression for prediction of psychological distress were displayed in Table 3 . From the univariate analyses, nationalities, age, sex, education, and employment status were

Table 1

Demographics of the respondents $(n=7091)$.

\begin{tabular}{|c|c|c|}
\hline & Mean/Count & SD/Proportion \\
\hline Age & 33.2 & 12.1 \\
\hline \multicolumn{3}{|l|}{ Sex } \\
\hline Male & 2854 & $40.2 \%$ \\
\hline Female & 4237 & $59.8 \%$ \\
\hline \multicolumn{3}{|l|}{ Religion } \\
\hline Buddhism & 1127 & $15.9 \%$ \\
\hline Christianity & 546 & $7.7 \%$ \\
\hline Hinduism & 754 & $10.6 \%$ \\
\hline Islam & 4359 & $61.5 \%$ \\
\hline Others & 305 & $4.3 \%$ \\
\hline \multicolumn{3}{|l|}{ Education } \\
\hline Primary & 172 & $2.4 \%$ \\
\hline Secondary & 2122 & $29.9 \%$ \\
\hline Tertiary & 4794 & $67.7 \%$ \\
\hline \multicolumn{3}{|l|}{ Employment } \\
\hline Employed & 4051 & $57.2 \%$ \\
\hline Unemployed & 1583 & $22.3 \%$ \\
\hline Student & 1457 & $20.5 \%$ \\
\hline \multicolumn{3}{|l|}{ Nationality } \\
\hline Bangladesh & 460 & $6.5 \%$ \\
\hline Egypt & 256 & $3.6 \%$ \\
\hline India & 378 & $5.3 \%$ \\
\hline Indonesia & 1067 & $15.1 \%$ \\
\hline Iran & 1160 & $16.4 \%$ \\
\hline Malaysia & 1197 & $16.9 \%$ \\
\hline Myanmar & 415 & $5.9 \%$ \\
\hline Nepal & 241 & $3.4 \%$ \\
\hline Philippines & 357 & $5.0 \%$ \\
\hline Sri Lanka & 328 & $4.6 \%$ \\
\hline Thailand & 356 & $5.0 \%$ \\
\hline Turkey & 456 & $6.4 \%$ \\
\hline Vietnam & 420 & $5.9 \%$ \\
\hline
\end{tabular}

Table 2

Prevalence of distress respondents across different countries and other socioeconomic characteristics $(\mathrm{n}=7091)$.

\begin{tabular}{|c|c|c|c|}
\hline Factors & $\begin{array}{l}\text { Distress } \\
\text { (count) }\end{array}$ & $\begin{array}{l}\text { Total } \\
\text { population }\end{array}$ & $\begin{array}{l}\text { Prevalence of distress (in } \\
\%)\end{array}$ \\
\hline \multicolumn{4}{|l|}{ Country } \\
\hline Vietnam & 397 & 420 & $94.5 \%$ \\
\hline Egypt & 164 & 256 & $64.1 \%$ \\
\hline Bangladesh & 259 & 460 & $56.3 \%$ \\
\hline Philippines & 185 & 357 & $51.8 \%$ \\
\hline Iran & 599 & 1160 & $51.6 \%$ \\
\hline Myanmar & 209 & 415 & $50.4 \%$ \\
\hline Turkey & 192 & 456 & $42.1 \%$ \\
\hline Indonesia & 432 & 1067 & $40.5 \%$ \\
\hline India & 148 & 378 & $39.2 \%$ \\
\hline Malaysia & 430 & 1197 & $35.9 \%$ \\
\hline Thailand & 100 & 356 & $28.1 \%$ \\
\hline Sri Lanka & 88 & 328 & $26.8 \%$ \\
\hline Nepal & 34 & 241 & $14.1 \%$ \\
\hline $\begin{array}{l}\text { Chi square } \\
\text { statistic }\end{array}$ & $740.84 * * *$ & & \\
\hline \multicolumn{4}{|l|}{ Sex } \\
\hline Male & 1204 & 2854 & $42.2 \%$ \\
\hline Female & 2034 & 4237 & $48.0 \%$ \\
\hline $\begin{array}{l}\text { Chi square } \\
\text { statistic }\end{array}$ & $22.60 * * *$ & & \\
\hline \multicolumn{4}{|l|}{ Education } \\
\hline $\begin{array}{l}\text { Primary/ } \\
\text { Secondary }\end{array}$ & 970 & 2294 & $42.3 \%$ \\
\hline Tertiary & 2268 & 4794 & $47.3 \%$ \\
\hline $\begin{array}{l}\text { Chi square } \\
\text { statistic }\end{array}$ & $15.79 * * *$ & & \\
\hline \multicolumn{4}{|l|}{ Employment } \\
\hline Employed & 1876 & 4051 & $46.3 \%$ \\
\hline Unemployed & 750 & 1583 & $47.4 \%$ \\
\hline Student & 610 & 1457 & $41.9 \%$ \\
\hline $\begin{array}{l}\text { Chi square } \\
\text { statistic }\end{array}$ & $10.22 * *$ & & \\
\hline
\end{tabular}

Note: Chi square test statistic and $\mathrm{p}$ value ${ }^{*} \mathrm{p}<0.05,{ }^{* *} \mathrm{p}<0.01,{ }^{* * *} \mathrm{p}<0.001$.

associated with having psychological distress. Multivariable model 1 predicted psychological distress adjusted for countries, age, and sex whereby model 2 had education and employment status added to variables in model 1 .

Multivariable models suggested that countries, sex, and education level were significant factors in predicting psychological distress in this pandemic. With Nepal as referent, Vietnam had the highest odds of reporting distress (adjusted OR 107.91, 95\% CI 61.46-189.46) while Sri Lanka reported the lowest odds of having psychological distress (adjusted OR 2.23, 95\% CI 1.42-3.50). Women had 30\% higher odds of having reported psychological distress (adjusted OR 1.30, 95\% CI 1.16-1.45) while those with tertiary education were less likely to report psychological distress compared to those with lower level of education (adjusted OR 0.85, 95\% CI 0.74-0.97).

\section{Discussion}

This study demonstrates the importance of assessing psychological distress and mental health effects in the general population during a global pandemic. Studies on mental health effects during the current COVID-19 pandemic showed that healthcare workers are mostly at risk of psychological sequelae such as psychological distress, anxiety, depression, and other mental health issues during such outbreaks by being on the frontline. ${ }^{17-19}$ Nevertheless, its impact on non-healthcare workers is also significant, and is worth addressing. ${ }^{20}$

It has long been disproven that psychological distress only concerns those in affluent countries. However, studies have shown that its effects are widespread and global. ${ }^{21-23}$ Nevertheless, a comparative study on the effects of pandemic on the mental health of non-healthcare workers in different countries across continents especially among developing nations have not been much attempted. This study, done on such a scale, 
Table 3

Univariate and multivariable logistic regression for COVID-19 distress.

\begin{tabular}{|c|c|c|c|c|c|c|}
\hline \multirow[t]{2}{*}{ Factors } & \multicolumn{2}{|l|}{ Univariate } & \multicolumn{2}{|l|}{ Multivariable model $1^{\mathrm{a}}$} & \multicolumn{2}{|l|}{ Multivariable model $2^{\mathrm{b}}$} \\
\hline & Crude OR $(95 \% \mathrm{CI})$ & p-value & Adjusted OR (95\% CI) & p-value & Adjusted OR (95\% CI) & p-value \\
\hline \multicolumn{7}{|l|}{ Nationality } \\
\hline Nepal & Reference & & Reference & & Reference & \\
\hline Bangladesh & $7.85(5.22-11.78)$ & $<0.001$ & $7.42(4.93-11.18)$ & $<0.001$ & $8.12(5.34-12.34)$ & $<0.001$ \\
\hline Egypt & $10.85(6.97-16.91)$ & $<0.001$ & $9.62(6.15-15.04)$ & $<0.001$ & $10.54(6.68-16.61)$ & $<0.001$ \\
\hline India & $3.92(2.58-5.95)$ & $<0.001$ & $3.78(2.48-5.74)$ & $<0.001$ & $4.17(2.72-6.39)$ & $<0.001$ \\
\hline Indonesia & $4.14(2.82-6.07)$ & $<0.001$ & $3.81(2.60-5.60)$ & $<0.001$ & $3.65(2.48-5.38)$ & $<0.001$ \\
\hline Iran & $6.50(4.44-9.51)$ & $<0.001$ & $5.68(3.86-8.34)$ & $<0.001$ & $6.23(4.20-9.24)$ & $<0.001$ \\
\hline Malaysia & $3.41(2.33-5.00)$ & $<0.001$ & $3.11(2.12-4.56)$ & $<0.001$ & $3.29(2.23-4.86)$ & $<0.001$ \\
\hline Myanmar & $6.18(4.10-9.31)$ & $<0.001$ & $5.90(3.91,8.90)$ & $<0.001$ & $6.08(4.02-9.19)$ & $<0.001$ \\
\hline Philippines & 6.55 (4.31-9.95) & $<0.001$ & $6.10(4.01-9.28)$ & $<0.001$ & $6.58(4.30-10.07)$ & $<0.001$ \\
\hline Sri Lanka & $2.23(1.44-3.46)$ & $<0.001$ & $2.01(1.30-3.13)$ & $<0.001$ & $2.23(1.42-3.50)$ & $<0.001$ \\
\hline Thailand & $2.38(1.55-3.66)$ & $<0.001$ & $2.23(1.45-3.43)$ & $<0.001$ & $2.44(1.57-3.79)$ & $<0.001$ \\
\hline Turkey & $4.43(2.95-6.66)$ & $<0.001$ & $4.44(2.95-6.68)$ & $<0.001$ & $4.50(2.99-6.78)$ & $<0.001$ \\
\hline Vietnam & 105.09 (60.32-183.09) & $<0.001$ & 99.54 (57.09-173.55) & $<0.001$ & $107.91(61.46-189.46)$ & $<0.001$ \\
\hline Age & $0.991(0.987-0.995)$ & $<0.001$ & $0.997(0.993-1.001)$ & 0.155 & $0.996(0.991-1.001)$ & 0.123 \\
\hline Sex (Female) & $1.26(1.15-1.39)$ & $<0.001$ & $1.27(1.14-1.42)^{* * *}$ & $<0.001$ & $1.30(1.16-1.45)$ & $<0.001$ \\
\hline \multicolumn{7}{|l|}{ Education } \\
\hline Primary/Sec & Reference & & & & Reference & \\
\hline Tertiary & $1.22(1.10-1.35)$ & $<0.001$ & & & $0.85(0.74-0.97)$ & 0.018 \\
\hline \multicolumn{7}{|l|}{ Employment } \\
\hline Student & Reference & & & & Reference & \\
\hline Employed & $1.20(1.06-1.35)$ & 0.003 & & & $1.03(0.88-1.20)$ & 0.744 \\
\hline Unemployed & $1.25(1.08-1.44)$ & 0.002 & & & $0.98(0.82-1.17)$ & 0.820 \\
\hline
\end{tabular}

$* \mathrm{p}<0.05, * * \mathrm{p}<0.01, * * * \mathrm{p}<0.001$.

a Nationality, age and sex $(n=7091)$.

b Model $1+$ education and employment $(n=7088)$.

managed to do just that. It is able to inform us on how the prevalence of psychological distress varies across non-developed countries, while controlling for the cause of distress.

In this study, we were able to ascertain that, as the result of COVID19 outbreak, Vietnam had the highest prevalence of psychological distress followed by Egypt, where Nepal had the least. The emergence of the COVID-19 outbreak, misinformation and fake news inundating social media platforms have sparked coronavirus fears locally and globally. In Vietnam, rumors, such as lockdowns of entire cities, COVID-19 deaths, or shortages of facemasks or food, spread on social media networks are serious public concerns. These have inflamed the COVID-19 panic and confusion, stockpiling of foods and essential supplies, and people rushing to pharmacies for face mask purchases. At the early phase of the outbreak, the Vietnamese Prime Minister has signed a decree stipulating sanctions against those disseminating fake news and misinformation on social media. ${ }^{24}$

The total number of COVID-19 confirmed cases reported from Nepal till April 2020 was the lowest among the study countries with no deaths (Table 4). The small sample size and largely represent the urban population were the most probable reason behind low distress level in Nepal compared to other countries in study. However, a similar community survey done on April 2020 in Nepal revealed that the prevalence of anxiety, depression and stress were $14 \%, 7 \%$ and $5 \%$ respectively. ${ }^{25}$

Countries such as the Philippines, Turkey, as well as Malaysia were placed somewhere in between. Unfortunately, it is beyond the scope of this study to enlighten us on why this is so. However, previous studies have looked at predictors of psychological distress have found that one of the most important factors is the negative perception on the consequence of the pandemic on their ability to satisfy their most basic needs such as financial security and physical safety. ${ }^{11,26}$ It is possible that people in countries with higher prevalence of psychological distress were struggling with these basic necessities even prior to the outbreak. Another strong predictor is social connectedness and social support. ${ }^{27,28}$ In countries such as the Philippines and Malaysia, there exists a strong collectivistic culture which may help to lessen the impact of the outbreak on mental health.

The protective effect of resilience obliges a special mention. Resilience is the ability to sustain or reinstate their mental health when faced

Table 4

Countries with reported laboratory-confirmed COVID-19 cases and deaths. Data as of 17 April 2020* https://www.who. int/publications-detail/infection-prevention-and-control-during-health-care-when-novel-coronavirus-(ncov)- infection-is-suspected-20200125.

\begin{tabular}{|c|c|}
\hline Nationality & Total Number of confirmed COVID-19 cases \\
\hline Iran & 77995 \\
\hline Turkey & 74193 \\
\hline India & 13387 \\
\hline Philippines & 5660 \\
\hline Indonesia & 5516 \\
\hline Malaysia & 5182 \\
\hline Thailand & 2700 \\
\hline Egypt & 2673 \\
\hline Bangladesh & 1572 \\
\hline Vietnam & 268 \\
\hline Sri Lanka & 238 \\
\hline Myanmar & 85 \\
\hline Nepal & 16 \\
\hline
\end{tabular}


with significant hardship. ${ }^{29}$ Studies among students have found that high levels of resilience protected them from developing psychological distress during periods of extreme stress. ${ }^{30}$ Likewise, in communities ravaged by war, natural disasters and other adversities also had similar experiences. ${ }^{31-33}$ About five years ago, Nepal was devastated by a strong earthquake. It is possible that, in the wake of such an event, the Nepalese had become a resilient nation, so much so that it was least affected by psychological distress in the recent pandemic.

The researchers also found that after adjusting for confounders, gender and educational attainment were the only factors which could significantly alter the risk of psychological distress. Females are at a higher risk of getting psychological distress compared to males. This is a fairly established circumstance, one that had been demonstrated by previous studies. ${ }^{21,30}$ Those with lower educational attainment also have an increased risk of developing psychological distress and this finding is similar to a previous study in outbreak situations. ${ }^{11}$

Psychological distress may be a state which commonly occurs following stressful situations. Most of the time, it is transient, but sometimes may last longer than a few weeks. When this happens, the person may be at risk of developing other mental illnesses such as depression, anxiety, and posttraumatic stress disorder. ${ }^{11}$ Interestingly, researches have also linked psychological distress with cardiovascular disease, arthritis, and chronic obstructive pulmonary diseases. ${ }^{34}$ Furthermore, this association persisted even after adjusting for factors such as smoking status, exercise, and diet. This suggests that psychological sequalae of the COVID-19 pandemic may be endured long after the condition itself, and, if not, addressed may impediment the already overburdened health service. ${ }^{26}$

The main strength of this study is the inclusion of the large number of respondents from different corners of the globe. However, since the recruitment of these respondents was done through convenience sampling, the presence of bias may limit its findings. Non-respondent population, such as severely distressed patients without interest to participate in the survey or low digital literate participants, might affect the generalizability of the findings in these populations. However, efficiency of data collection, lower cost and acceptability of the recruitment of online survey could provide the useful alternative for the formal regional or national survey. ${ }^{35}$ With such a large number and widespread participation, the findings of this study are difficult to be ignored but need of further research for the in-depth understanding of the issue.

\section{Funding}

This research received no grant or funding from any funding agency.

\section{Declaration of competing interest}

The authors declare no conflict of interest.

\section{References}

1 WHO. Mental health and psychosocial considerations during the COVID-19 outbreak. https://www.who.int/docs/default-source/coronaviruse/mental-health-consid erations.pdf?sfvrsn=6d3578af_2; 2020.

2 Zhu N, Zhang D, Wang W, et al. A novel coronavirus from patients with pneumonia in China, 2019. N Engl J Med. 02 2020;382(8):727-733. https://doi.org/10.1056/ NEJMoa2001017.

3 Gandubert C, Scali J, Ancelin ML, et al. Biological and psychological predictors of posttraumatic stress disorder onset and chronicity. A one-year prospective study. Neurobiol Stress. Jun 2016;3:61-67. https://doi.org/10.1016/j.ynstr.2016.02.002.

4 Miles SH. Kaci Hickox: public health and the politics of fear. Am J Bioeth. 2015;15(4): 17-19. https://doi.org/10.1080/15265161.2015.1010994.

5 Yoon MK, Kim SY, Ko HS, Lee MS. System effectiveness of detection, brief intervention and refer to treatment for the people with post-traumatic emotional distress by MERS: a case report of community-based proactive intervention in South Korea. Int J Ment Health Syst. 2016;10:51. https://doi.org/10.1186/s13033-0160083-5.

6 Marzo RR, Singh A, Mukti RF. A survey of psychological distress among Bangladeshi people during the COVID-19 pandemic. Clinical Epidemiology and Global Health. Jan 2021;10:1016. https://doi.org/10.1016/j.cegh.2020.100693.
7 Marzo RR, Villanueva 3rd EQ, Faller EM, Baldonado AM. Factors associated with psychological distress among Filipinos during coronavirus disease-19 pandemic crisis. Open Access Maced J Med Sci. 2020 Nov 07;8(T1):309-313. https://doi.org/ 10.3889/oamjms.2020.5146.

8 El-Abasari RA, Marzo RR, Abdelaziz H, Boraii S, Abdelaziz DH. Evaluating the psycchological distress of the coronavirus disease 2019 pandemic in Egypt. European Journal of Molecular \&Clinical Medicine. Dec 2020;7:1-12. https://ejmcm.co $\mathrm{m} /$ article_1675.html.

9 Respati T, Irasanti SN, Sartika D, Akbar IB, Marzo RR. A nationwide survey of psychological distress among Indonesian residents during the COVID-19 pandemic. Int J Publ Health Sci. Jan 2021. https://doi.org/10.11591/ijphs.v10i1.20609.

10 Htay MNN, Marzo RR, AlRifai A, et al. Immediate impact of COVID-19 on mental health and its associated factors among healthcare workers: a global perspective across 31 countries. J Glob Health. 2020;10, 020382. https://doi.org/10.7189/ jogh.10.020381.

11 Brooks SK, Webster RK, Smith LE, et al. The psychological impact of quarantine and how to reduce it: rapid review of the evidence. Lancet. 03 2020;395(10227): 912-920. https://doi.org/10.1016/S0140-6736(20)30460-8.

12 Bosqui TJ, Kouvonen A, Kawabata Y. Ethnic inequalities in psychological distress: a population data linkage study on the pacific Island of Guåhån/Guam. J Immigr Minority Health. Oct 2019;21(5):1026-1034. https://doi.org/10.1007/s10903-0180815-5.

13 Atkin AL, Tran AGTT. The roles of ethnic identity and metastereotype awareness in the racial discrimination-psychological adjustment link for Asian Americans at predominantly White universities. Cult Divers Ethnic Minor Psychol. Feb 2020. https://doi.org/10.1037/cdp0000323.

14 Bamford J, Klabbers G, Curran E, Rosato M, Leavey G. Social capital and mental health among black and minority ethnic groups in the UK. J Immigr Minority Health. Jul 2020. https://doi.org/10.1007/s10903-020-01043-0.

15 Islam FMA. Psychological distress and its association with socio-demographic factors in a rural district in Bangladesh: a cross-sectional study. PloS One. 2019;14(3), e0212765. https://doi.org/10.1371/journal.pone.0212765.

16 Qiu J, Shen B, Zhao M, Wang Z, Xie B, Xu Y. A nationwide survey of psychological distress among Chinese people in the COVID-19 epidemic: implications and policy recommendations. Gen Psychiatr. 2020;33(2), e100213. https://doi.org/10.1136/ gpsych-2020-100213.

17 Burdorf A, Porru F, Rugulies R. The COVID-19 (Coronavirus) pandemic: consequences for occupational health. Scand J Work Environ Health. 05 2020;46(3): 229-230. https://doi.org/10.5271/sjweh.3893.

18 Wang S, Wen X, Dong Y, Liu B, Cui M. Psychological influence of coronovirus disease 2019 (COVID-19) pandemic on the general public, medical workers, and patients with mental disorders and its countermeasures. Psychosomatics. May 2020. https:// doi.org/10.1016/j.psym.2020.05.005.

19 Zhang SX, Liu J, Jahanshahi AA, Nawaser K, Li J, Alimoradi H. When the Storm Is the Strongest: Healthcare Staff's Health Conditions and Job Satisfaction and Their Associated Predictors during the Epidemic Peak of COVID-19. medRxiv; 2020.

20 Ho CS, Chee CY, Ho RC. Mental health strategies to combat the psychological impact of COVID-19 beyond paranoia and panic. Ann Acad Med Singapore. 03 2020;49(3): 155-160.

21 Aslam N, Kamal A. Coping strategies as a predictors of psychological distress and post traumatic Growth among flood affected Individuals. Journal of Alcoholism \& Drug Dependence. 2015;3(1). https://doi.org/10.4172/2329-6488.1000181.

22 Uddin MN, Bhar S, Al Mahmud A, Islam FMA. Psychological distress and quality of life: rationale and protocol of a prospective cohort study in a rural district in Bangladesh. BMJ Open. Sep 2017;7(9), e016745. https://doi.org/10.1136/bmjopen2017-016745.

23 Wang Y, Wang P. Perceived stress and psychological distress among Chinese physicians: the mediating role of coping style. Medicine (Baltim). Jun 2019;98(23), e15950. https://doi.org/10.1097/MD.0000000000015950.

24 Nguyen THD, Vu DC. Impacts of the COVID-19 pandemic upon mental health: perspectives from Vietnam. Psychol Trauma. Jul 2020;12(5):480-481. https://doi. org/10.1037/tra0000694.

25 Shrestha DB, Thapa BB, Katuwal N, et al. Psychological distress in Nepalese residents during COVID-19 pandemic: a community level survey. BMC Psychiatr. 10 2020;20 (1):491. https://doi.org/10.1186/s12888-020-02904-6.

26 Sanderson WC, Arunagiri V, Funk AP, et al. The nature and treatment of pandemicrelated psychological distress. J Contemp Psychother. Jun 2020:1-13. https://doi.org/ 10.1007/s10879-020-09463-7.

27 Chand RM, Pidgeon AM. Psychosocial predictors of psychological distress among Australian university students. Journal of Harmonized Research in Medical and Health Science. 2017;4(3).

28 Hampton KN. Social media and change in psychological distress over time: the role of social causation. J Computer-Mediated Commun. 2019;24(5):205-222. https://doi. org/10.1093/jcmc/zmz010.

29 Macedo T, Wilheim L, Gonçalves R, et al. Building resilience for future adversity: a systematic review of interventions in non-clinical samples of adults. BMC Psychiatry. Aug 2014;14:227. https://doi.org/10.1186/s12888-014-0227-6.

30 Jv Agteren, Woodyatt L, Iasiello M, Rayner J, Kyrios M. Make it measurable: assessing psychological distress, Wellbeing and resilience at scale in higher education. Student Success Journal. 2019;10(3):1-13. https://doi.org/10.5204/ssj. v10i3.1411.

31 Lowe SR, Sampson L, Gruebner O, Galea S. Psychological resilience after Hurricane Sandy: the influence of individual- and community-level factors on mental health after a large-scale natural disaster. PloS One. 2015;10(5), e0125761. https://doi.org/ 10.1371/journal.pone.0125761. 
32 Panter-Brick C, Grimon MP, Kalin M, Eggerman M. Trauma memories, mental health, and resilience: a prospective study of Afghan youth. JCPP ( $\mathrm{J}$ Child Psychol Psychiatry). Jul 2015;56(7):814-825. https://doi.org/10.1111/jcpp.12350.

33 Vilete L, Figueira I, Andreoli SB, et al. Resilience to trauma in the two largest cities of Brazil: a cross-sectional study. BMC Psychiatry. Sep. 2014;14:257. https://doi.org/ 10.1186/s12888-014-0257-0.
34 McLachlan KJJ, Gale CR. The effects of psychological distress and its interaction with socioeconomic position on risk of developing four chronic diseases. $J$ Psychosom Res. 06 2018;109:79-85. https://doi.org/10.1016/j.jpsychores.2018.04.004.

35 Heen MSJ, Lieberman JD, Miethe TD. A Comparison of Different Onl Ine Sampling Approaches for Generating National Samples. Center For Crime And Justice Policy; 2014, 2014-01. 